http://dx.doi.org/10.18359/ravi.2674

\title{
Relación entre la creatividad, la memoria inmediata y lógica en relación con el rendimiento académico en la educación secundaria ${ }^{1}$
}

\author{
Ana María Ramos Moreno ${ }^{2}$, Verónica López-Fernández ${ }^{3}$ y Fátima Llamas-Salguero ${ }^{4}$ \\ Universidad Internacional de La Rioja (UNIR), España.
}

Recibido, Noviembre 18 de 2016

Concepto evaluación, enero 24 de 2017

Aceptado, enero 30 de 2017

\author{
Referencia: Ramos Moreno, A.; López-Fernández, V. \& \\ Llamas-Salguero, F. (2017). "Relación entre la creatividad, \\ la memoria inmediata y lógica en relación con el rendimiento \\ académico en la educación secundaria". Revista Academia y \\ Virtualidad, 10, (1), 123-130
}

\section{Resumen}

La presente investigación pretende analizar la relación entre creatividad y la memoria (inmediata y lógica), y a su vez éstas con el rendimiento académico en adolescentes de educación secundaria. La muestra estuvo compuesta por 51 estudiantes de $4^{\circ}$ de educación secundaria de 15 a 16 años, en un colegio concertado en la Región de Murcia. El instrumento utilizado para evaluar la creatividad fue el test CREA, mientras que para evaluar la memoria lógica se utilizó el subtest 6, memorización lógica, Luria-DNA; y para evaluar la memoria inmediata fue subtest 5, memoria inmediata de Luria-DNA. El rendimiento académico se obtuvo a través de las notas de las diferentes asignaturas. Para conocer la relación entre las variables se calculó la correlación de Pearson y se hizo un análisis descriptivo a fin de establecer la media, la desviación, el máximo y el mínimo de cada variable. Los resultados indicaron que solamente existía una correlación significativa entre memoria inmediata y rendimiento académico, mientras que entre las demás no hubo relación significativa. Finalmente, se discuten los resultados encontrados y se proponen nuevas líneas de investigación.

Palabras clave: creatividad, memoria lógica, memoria inmediata, rendimiento académico, variables.

\footnotetext{
${ }^{1}$ Artículo resultado de investigación.

${ }^{2}$ Máster en Neuropsicología y Educación, Universidad Internacional de La Rioja (UNIR). anika_rm82@hotmail.com

${ }^{3}$ Doctora en Psicología; Docente e Investigadora, Universidad Internacional de La Rioja (UNIR). veronica.lopez@unir.net

${ }^{4}$ Doctora en Pedagogía; Docente e Investigadora, Universidad Internacional de La Rioja (UNIR). fatima.1lamas@unir.net
} 


\title{
A relationship among creativity, immediate-and-logic memory and academic achievement in secondary school
}

\begin{abstract}
This research aims to analyze a relationship between creativity and immediate-and-logical memory, and in turn these ones related to the academic achievement by adolescents in secondary school. The sample included fifty-one 4th-graders, 15-16 years old in a Murcia school. The instrument to evaluate the creativity was CREA test while the logic memory was evaluated using subtest 6, logical memorization, Luria-DNA; and the immediate memory was evaluated using subtest 5 , immediate memory Luria-DNA. The academic performance was got through the marks of the different subjects. To know the relationship between the variables, the Pearson correlation was calculated and a descriptive analysis was made in order to establish the mean, the deviation, and the maximum and minimum of each variable. The results show there is only a significant correlation between immediate memory and academic performance, while the others show there is not a significant relation. Finally, the results are discussed and new research lines have been proposed.
\end{abstract}

Keywords: creativity, logic memory, immediate memory, academic performance, variables.

\section{Relação entre a criatividade, a memória imediata e lógica em relação com o rendimento académico na educação secundária.}

\section{Resumo}

A presente pesquisa tenta de analisar a relação entre criatividade e a memória (imediata e lógica), e por sua vez estas com o rendimento académico em adolescentes de educação secundária. A mostra esteve composta por 51 estudantes de $4^{\circ}$ de educação secundária entre 15 e 16 anos, de um colégio concertado na região de Murcia. O instrumento utilizado para avaliar a criatividade foi o teste CREA, enquanto para avaliar a memória lógica utilizouse o sob teste 6, memorização lógica, Luria- DNA; e para avaliar a memória imediata foi o sob teste 5, memória imediata de Luria-DNA. O rendimento acadêmico obteve-se através das notas das diferentes matérias. Para conhecer a relação entre as variáveis calculou-se a correlação de Pearson e fez-se uma análise descritiva a fim de estabelecer a média, o desvio, o máximo e o mínimo de cada variável. Os resultados indicaram que só existia uma correlação significativa entre memória imediata e rendimento académico, enquanto entre as demais não teve relação significativa. No final se discutem os resultados achados e se propõem novas líneas de pesquisa.

Palavras chave: criatividade, memória lógica, memória imediata e rendimento académico, variáveis. 


\section{Marco teórico}

No es un dato novedoso decir que España tiene un alto fracaso escolar o un alto abandono escolar. En la publicación que realizó el Ministerio de Educación el 24 de septiembre de 2015, se puede ver con exactitud las cifras por Comunidades Autónomas del abandono escolar temprano en 2014, lo que refleja también el porcentaje de abandono educativo temprano en los países de la Unión Europea, quedando España en última posición, con un porcentaje del $21,9 \%$.

Ciertos factores neuropsicológicos están relacionados con el fracaso escolar: problemas visuales, problemas auditivos, problemas de memoria, problemas de motricidad y problemas de lenguaje (Martín Lobo, 2006). En el presente trabajo se pretende acercar el rendimiento académico a la neuropsicología, de tal manera que se pretende implicar a la memoria y a la creatividad.

Robinson (2015), considerado un experto en creatividad y autor de libros relacionados con la creatividad, habla de la relación existente entre la creatividad y las escuelas. Éste, asimismo, responsabiliza a las escuelas de estar acabando con la creatividad en los niños que se encuentran en el escenario pedagógico, ya que se les impone un sistema educativo jerarquizado con unas normas que todos los estudiantes deben cumplir. Asimismo, afirma que tampoco se les da la oportunidad de elegir lo que realmente les apasiona. Habla también de la importancia de estar donde él llama elemento y los beneficios que aporta para llegar a la creatividad. Además, para Robinson, la creatividad y la inteligencia están estrechamente unidas.

Por otra parte, resulta importante anotar que la memoria está implicada en el aprendizaje, pues sin memoria no habría aprendizaje. Ya que la memoria tiene la disposición de retener la información que se quiera conservar, ya sea a corto o largo plazo; memoria y aprendizaje son dos procesos cerebrales fuertemente ligados.

Actualmente se divulgan gran cantidad de materiales que hacen énfasis en la necesidad de entrenamiento de la memoria lógica y en el uso de diferentes recursos a partir de los cuales se debe estimular para garantizar el estudio eficiente (López, Jústiz y Cuenca, 2013). Y no es de extrañar ya que, según López et al. (2013) es la memoria lógica la que requiere una mayor atención para mejorar su uso, pues ésta permite la comprensión del significado del material que se estudia, la selección de ideas importantes, pudiendo relacionarlas, organizarlas y estructurarlas para facilitar su conservación y actualización.

De otro lado, Conde-Guzón, QuirósExpósito, Conde-Guzón y BartoloméAlbistegui (2014) plantean que una buena memoria inmediata posibilita que el esquema articulatorio se recuerde fácilmente llegando a la automatización. Otros autores con anterioridad han investigado y analizado la memoria y el rendimiento académico. Es el caso Del Valle y Urquijo (2015), quienes correlacionan las estrategias de codificación mnésica con la capacidad de aprendizaje y el desempeño académico. De tal manera que la capacidad de aprendizaje y la utilización de estrategias de codificación mnésica, en un uso mayor de estrategias mnésicas, se asocia a un mayor rendimiento académico. Al respecto, Restrepo, Roca, Sucerquia y Herrera (2012) también coinciden en su estudio al evaluar las correlaciones entre la personalidad infantil normal y la memoria auditiva inmediata en un grupo de escolares con rendimiento académico normal, lo que articula una correlación significativa entre la inteligencia baja-alta y la memoria lógica.

Retomando la variable creatividad, para Beghetto y Kaufman (2009) el aprendizaje académico y la creatividad deben ser objetivos superpuestos que pueden llevarse de forma simultánea en los programas académicos. Nami, Marsooli y Ashouri (2014) realizaron un análisis donde su objetivo era corroborar si existía una relación entre creatividad y rendimiento académico. Finalmente, en los resultados se pudo comprobar que sí existe una correlación entre ambas variables. De esta manera, se confirma que a mayor creatividad mayor rendimiento académico. 
Campos, Calderón y González (2000) también investigaron la relación entre creatividad y rendimiento académico.

Así las cosas, promover la creatividad dentro del ámbito educativo tiene impactos positivos en la vida personal de las personas, pues se pueden generar innovaciones dentro de la educación, lo que tendría un impacto si se difunde en distintos contextos y situaciones. Por tanto, estimular contextos creativos no sólo es relevante para los sujetos y sus vidas particulares, sino determinante para las sociedades y los problemas que éstas atraviesan (Elisondo, 2015).

Al respecto, Guilford (1967) propone un modelo de proceso creativo para la solución de problemas que consta de cinco fases. La novedad en este proceso es que incluye el papel de la memoria para mostrar lo que ocurre en todo momento a lo largo del proceso de solución de problemas, y este proceso puede ser influido por la información que el sujeto tiene almacenada en la memoria.

Como punto de partida de esta afirmación cabe destacar, tal como señala Serrano (2013), que no se puede afirmar que la creatividad y memoria estén siempre relacionadas. No obstante, según este autor, no debemos olvidar que la creatividad se nutre en gran parte de aspectos o elementos vinculados con los procesos mnésicos, ya ubicados y almacenados en el cerebro. Como expresa Marina (1994), en todo acto creativo se construye desde la memoria, esto es, se ha demostrado que la memoria tiene un papel prioritario en las primeras etapas del proceso creativo (preparación, incubación [...]), y este inicio para Landau (1987) implicaría la percepción de un problema y el acceso a las informaciones relacionadas con ese problema. Con base en lo comentado, este estudio tiene como objetivo general analizar la relación de la memoria lógica e inmediata, la creatividad $\mathrm{y}$ el rendimiento académico en una muestra de estudiantes de secundaria de una región española. Los objetivos específicos serían conocer el nivel de la muestra en cada variable de estudio. Así, se hace la hipótesis que existe relación estadísticamente significativa $\mathrm{y}$ positiva entre las variables de estudio.

\section{Procedimientos metodológicos}

\section{Muestra}

La muestra total elegida por conveniencia está formada por 51 alumnos de $4^{\circ}$ grado de Educación Secundaria, 32 chicos y 19 chicas $(62.7 \%$ hombres y $37.3 \%$ mujeres $)$ de 15 a 16 años de edad $(X=15.52$; d.t $=$ $.50)$. Los estudiantes pertenecen a un centro educativo católico, concertado en los niveles obligatorios (infantil, primaria, ESO) y privado en bachillerato. El centro educativo se encuentra en Cartagena (Murcia, España) y cuenta con estudiantes cuyas familias tienen un nivel socioeconómico medio en su mayoría, y alguna familia, alto.

\section{Diseño}

La investigación se basa en un método cuantitativo con un diseño no experimental, es un método correlacional, ya que se pretende conocer la presencia y grado de variación entre las variables.

\section{Variables e instrumentos utilizados}

- Test de inteligencia creativa CREA (Corbalán, Martínez, Donolo, Alonso, Tejerina y Limiñana, 2003): mide la inteligencia creativa a través de una generación de preguntas que el sujeto hace respecto a un estímulo evocador. $\mathrm{Su}$ aplicación puede ser individual o colectiva; el ámbito de aplicación es desde niños de 6 años hasta adultos incluso. Se administró la lámina A por ser apropiada a las edades de los sujetos de la muestra. Durante cuatro minutos los sujetos realizan preguntas sobre la lámina expuesta.

- Luria-DNA (Manga y Ramos, 2000) Subtest 5. Memoria inmediata: se midió la memoria inmediata a través de 11 ejercicios, donde los alumnos en el primer ejercicio trataban de recordar 10 palabras 
que se repetían en 5 ensayos; en el segundo ejercicio trataban de recordar una serie de números; en el tercer ejercicio trataban de ver si había diferencias entre dos imágenes dadas; en el cuarto se pretende representar unas figuras vistas durante unos segundos; en los ejercicios quinto, sexto y séptimo, intentan recordar palabras; en el octavo ejercicio, recordar dos frases; en el noveno ejercicio, tratan de recordar una serie de órdenes y reproducirlas; en el décimo, recordar una historia y repetirla; y en el undécimo ejercicio, recordar las instrucciones dadas anteriormente.

- Luria - DNA (Manga y Ramos, 2000) Subtest 6. Memorización lógica: se midió la memoria lógica mediante tres ejercicios. En el primero, los alumnos tratan de recordar la asociación de una imagen con una palabra; en el segundo intentan recordar la asociación entre una serie de palabras e imágenes, pero esta vez los alumnos eligen la imagen; finalmente, en el tercer ejercicio, se les darán varias frases y a partir de éstas dibujarán algo que les recuerde y después de los dibujos recordarán la frase.

El rendimiento académico se analizó a través de las notas de la primera evaluación y se observó la nota de cada asignatura: biología, lengua castellana y literatura, matemáticas, ética, ciencias sociales, ampliación de ciencias, inglés, física y química, educación física, francés o informática y religión del curso 2015/2016. Así se toma la nota media de todas las asignaturas. Tanto la prueba de memoria inmediata como de la memoria lógica se realizó por escrito ya que se hizo de manera grupal.

\section{Análisis de datos}

Para este ejercicio se analizaron los resultados descriptivos de cada una de las variables: mínimo, máximo, media y desviación típica. Con base en el objetivo del estudio que es investigar la relación entre creatividad y memoria (inmediata y lógica) y de éstas con el rendimiento académico, se calculó el coeficiente de correlación Pearson. Para ello, se tuvo en cuenta el valor de $p$, siendo el valor .05 el que indicaba una relación significativa entre variables. El análisis de los datos se llevó a cabo con el programa SPSS, versión 22.

\section{Resultados descriptivos}

En la tabla 1 aparecen los resultados descriptivos de cada una de las variables de estudio, así se da cuenta de los objetivos específicos.

Tabla 1. Resultados descriptivos.

\begin{tabular}{lcccc}
\hline \multicolumn{1}{c}{ Variables } & Media & Desviación típica & Máximo & Mínimo \\
\hline Creatividad & 9.96 & 4.07 & 23 & 3 \\
\hline Memoria inmediata & 8.85 & 0.68 & 9.75 & 6.75 \\
\hline Memoria lógica & 5.06 & 0.77 & 6 & 3 \\
\hline Media total & 5.97 & 1.77 & 9.1 & 3 \\
\hline
\end{tabular}

Fuente: Elaboración propia.

\section{Resultados correlacionales}

En la tabla 2, a continuación, se pueden observar los resultados correlacionales obtenidos tras calcular el coeficiente de correlación de Pearson. 
Tabla 2. Correlaciones de Pearson de las variables de estudio.

\begin{tabular}{|c|c|c|c|c|c|}
\hline & $\begin{array}{c}\text { Correlación } \\
\text { creatividad- } \\
\text { memoria lógica }\end{array}$ & $\begin{array}{c}\text { Correlación } \\
\text { creatividad- } \\
\text { memoria } \\
\text { inmediata }\end{array}$ & $\begin{array}{c}\text { Correlación } \\
\text { creatividad- } \\
\text { rendimiento } \\
\text { académico }\end{array}$ & $\begin{array}{c}\text { Correlación } \\
\text { memoria } \\
\text { lógica- } \\
\text { rendimiento } \\
\text { académico }\end{array}$ & $\begin{array}{c}\text { Correlación } \\
\text { memoria } \\
\text { inmediata- } \\
\text { rendimiento } \\
\text { académico }\end{array}$ \\
\hline $\begin{array}{c}\text { Correlación } \\
\text { Pearson }\end{array}$ & -0.50 & -.132 & -0.12 & .158 & .362 \\
\hline $\mathbf{P}$ & .730 & .356 & .932 & .267 & .009 \\
\hline
\end{tabular}

Fuente: Elaboración propia.

No existen correlaciones significativas positivas entre las variables, a excepción de la correlación significativa entre memoria inmediata y rendimiento académico. En la figura 1 donde se puede apreciar el gráfico de dispersión de las variables que correlacionan de forma positiva y significativa. Por tanto, la hipótesis se cumple de manera parcial.

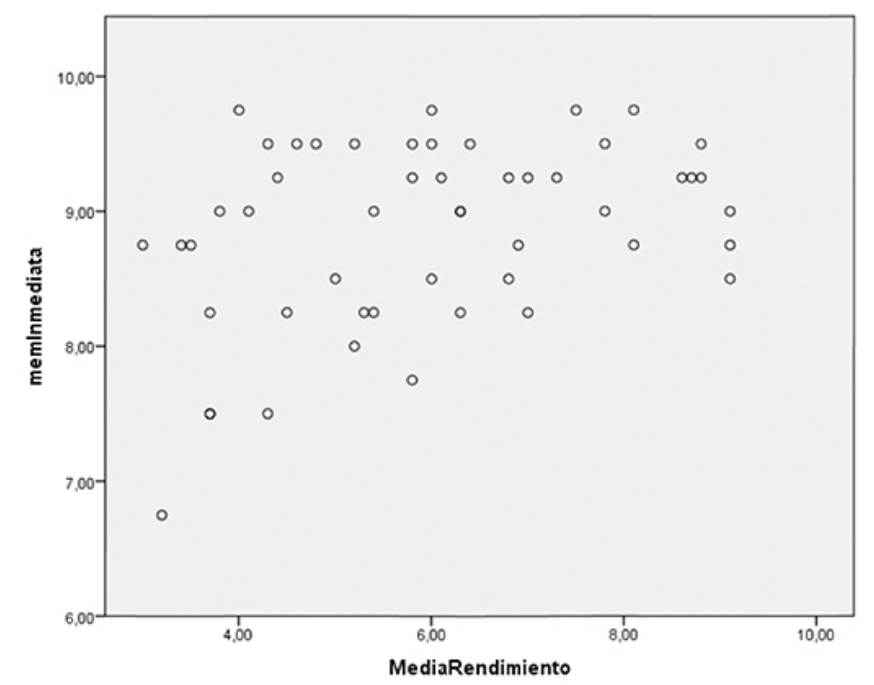

Figura 1. Correlación significativa memoria inmediata-rendimiento académico.

\section{Discusión y conclusiones}

Tanto el objetivo general como los objetivos específicos se han cumplido, ya que se investigó la relación entre creatividad y memoria (inmediata y lógica), y de éstas con el rendimiento académico, y para ello se evaluó y conoció el nivel de creatividad y ambas memorias; así, se conoce el rendimiento académico también a nivel de resultados descriptivos.

Respecto a las hipótesis planteadas, se acepta parcialmente la hipótesis nula a excepción de una de ellas, dado que en ese caso se acepta la alternativa, mostrando que existe correlación lineal estadísticamente significativa entre memoria inmediata y rendimiento académico. Estos hallazgos han tratado de arrojar luz sobre las relaciones entre las variables. A pesar de no haber encontrado relaciones entre creatividad y memoria, para otros autores el estudio de estas variables ha sido relevante. Así como señalan Furley y Memmert (2015), diversos estudios han presentado resultados opuestos mostrando correlaciones positivas, negativas e inexistentes. 
Quizás esta aparente falta de coherencia en los hallazgos, pueda deberse a que se evalúan en los estudios diferentes tipos de memoria y también diferentes tipos de creatividad. Guilford (1967), en su modelo de proceso creativo para la solución de problemas, incluyó la memoria como eje imprescindible en dicho procedimiento. Recientemente, López (2015) realizó una revisión teórica sobre la neuropsicología y la creatividad en las fases del proceso creativo y señaló la importancia de la memoria y la red por defecto en el proceso creativo en concreto en la fase de incubación de dicho proceso. Asimismo, Weisberg (1999) examinó la relación entre ambas variables y afirmó que el conocimiento específico de dominio es un requisito previo para la creatividad, relacionado con la memoria semántica.

En relación con el rendimiento académico y ambos tipos de memoria aquí evaluados, sólo se ha evidenciado relación de la memoria inmediata con el rendimiento, lo cual estaría en consonancia con estudios como el de Del Valle y Urquijo (2015), quienes correlacionan las estrategias de codificación mnésica con la capacidad de aprendizaje y el desempeño académico. Sin embargo, el hecho de no encontrar relación entre la memoria lógica y el rendimiento podría relacionarse con el hecho que las habilidades lógicas no son las únicas que se relacionan con el aprendizaje, ya que otras habilidades relacionadas con el pensamiento divergente también estarían relacionadas (Santos, 1986).

En referencia a futuras líneas de investigación sería recomendable realizar investigaciones que impliquen el estudio de las tres variables en muestras de mayor tamaño y de diferentes edades (creatividad, memoria inmediata $\mathrm{y}$ memoria lógica). Además, sería interesante investigar la relación de los diferentes tipos de memoria implicados en el rendimiento académico y en cada asignatura. Asimismo, se podrían investigar diferentes tipos de creatividad implicados en las diferentes asignaturas, así como la relación con las inteligencias múltiples y otras variables como las funciones ejecutivas y la atención. También resulta evidente que estos futuros estudios han de tratar de superar las limitaciones acontecidas en este trabajo, especialmente las concernientes al desequilibro de la muestra en función del género, lo que dificultaría la generalización de las conclusiones. Así como realizar dichos estudios con muestreos aleatorios que faciliten la representatividad de las muestras.

\section{Referencias}

Beghetto, R. A., y Kaufman, J. C. (2009). Intellectual Estuaries: Connecting Learning and Creativity in Programs of Advanced Academics. Journal of Advanced Academics, 20(2), 296-324.

Campos, G.A., Calderón, M. L., y González, G.M. Á., (2000). Imágenes mentales y creatividad: su relación con el rendimiento académico. Revista de Educación. (321), 343350.

Conde-Guzón, P., Quirós-Expósito, P., CondeGuzón, M. J., y Bartolomé-Albistegui, M. T. (2014). Perfil neuropsicológico de niños con dislalias: alteraciones mnésicas y atencionales. Anales de psicología, 30(3), 1105-1114.

Del Valle, M. V., y Urquijo, S. (2015). Relaciones de las estrategias de codificación mnésica y la capacidad de aprendizaje con el desempeño académico de estudiantes universitarios. Psicología Educativa, 21(1), 27-37.

Elisondo, R. C. (2015). La creatividad como perspectiva educativa. Cinco ideas para pensar los contextos creativos de enseñanza y aprendizaje. Revista Actualidades Investigativas en Educación, 15(3).

Furley, P., \& Memmert, D. (2015). Creativity and working memory capacity in sports: working memory capacity is not a limiting factor in creative decision making amongst skilled performers. Frontiers in Psychology, 6 . http://doi.org/10.3389/fpsyg.2015.00115 
Guilford, J. P. (1967). The nature of human intelligence. New York: McGraw-Hill.

Landau, E. (1987). El vivir creativo: teoría y práctica de la creatividad. Barcelona: Herder.

López, V. (2015). Importancia de la valoración de la creatividad desde su base neuropsicológica. En E. Vergara y P. Martín Lobo (Coord.). Procesos e instrumentos de evaluación neuropsicológica educativa. Madrid: Ministerio de Educación y Ciencia

López, M. M., Jústiz, G. M., y Cuenca, D. M. (2013). Métodos, procedimientos y estrategias para memorizar: reflexiones necesarias para la actividad de estudio eficiente. Humanidades Médicas, 13(3), 805-824.

Marina, J. A. (1994). Teoría de la inteligencia creadora. Barcelona: Anagrama.

Nami, Y., Marsooli, H., y Ashouri, M. (2014). The relationship between creativity and academic achievement. Procedia-Social and Behavioral Sciences, 114, 36-39.

Restrepo, J. E., Roca, Á., Sucerquia, S., y Herrera, S. (2012). Personalidad infantil y memoria auditiva inmediata en un grupo de escolares con rendimiento académico normal. Revista chilena de neuropsicología. 7(2), 6571.

Robinson, K. y Aronica, L. (2015). El elemento: Descubrir tu pasión lo cambia todo. Barcelona: Debolsillo.

Santos, M. R. (1986). Treinta y cinco años del pensamiento divergente: teoría de la creatividad de Guilford. Estudios de psicología, 7(27-28), 175-192.

Serrano, A. N (2013). Publicidad y memoria, una nueva visión desde las neurociencias. Tesis doctoral. Barcelona: Universidad de Ramon Llull.
Weisberg, R.W. (1999). Creativity and knowledge: A challenge to theories. In R.J. Sternberg (Ed.) Handbook of creativity. Cambridge: Cambridge University Press, 226-250. 